\title{
Cytoplasmic Localization of FAC Is Essential for the Correction of a Prerepair Defect in Fanconi Anemia Group C Cells
}

\author{
Hagop Youssoufian \\ Department of Medicine, Hematology-Oncology Division, Brigham and Women's Hospital, Harvard Medical School, Boston, \\ Massachusetts 02115
}

\begin{abstract}
Mutations in the gene defective in Fanconi anemia complementation group $\mathrm{C}, F A C$, are responsible for a subset of Fanconi anemia, a group of autosomal recessive disorders characterized by chromosomal instability, hypersensitivity to cross-linking agents, and cancer susceptibility. Although abnormalities in DNA repair have been suspected, localization of the $F A C$ gene product to the cytoplasm has cast doubt on such a mechanism. Monitoring of interstrand DNA cross-linking shows that the predominant defect in group $\mathrm{C}$ cells is in the initial induction of cross-links, not in repair synthesis. Both the cross-linking defect and the enhanced cytotoxicity of cross-linkers on Fanconi anemia group $\mathrm{C}$ cells are corrected completely by cytoplasmic isoforms of the FAC protein, but not by an isoform targeted to the nucleus. The ability of FAC to correct these phenotypic abnormalities reaches a maximum threshold despite overexpression leading to higher levels of cytosolic protein. These results demonstrate that cytoplasmic localization is essential for the intracellular activity of the FAC protein. It is proposed that this activity is coupled to a cytoplasmic defense mechanism against a specific class of genotoxic agents. (J. Clin. Invest. 1996. 97:2003-2010.) Key words: cross-linker • cytotoxicity - DNA repair • subcellular location
\end{abstract}

\section{Introduction}

Fanconi anemia $(\mathrm{FA})^{1}$ is an autosomal recessive disorder characterized by a wide array of congenital anomalies, bone marrow failure, and predisposition to cancer (1-4). The major cellular hallmark of FA is spontaneous chromosomal breakage accentuated by treatment with bifunctional alkylating agents (cross-linkers), such as mitomycin C (MMC) and diepoxybutane $(\mathrm{DEB} ; 4,5)$. The clinical phenotype is variable and may

Address correspondence to Hagop Youssoufian, M.D., Brigham and Women's Hospital, 221 Longwood Avenue, LMRC 620, Boston, MA 02115. Phone: 617-732-5464; FAX: 617-739-3324.

Received for publication 28 December 1995 and accepted in revised form 12 February 1996.

1. Abbreviations used in this paper: cross-linker, bifunctional alkylating agent; DEB, diepoxybutane; DRGE, denaturation-renaturation gel analysis; FA, Fanconi anemia; FA-C, Fanconi anemia complementation group $\mathrm{C}$; MMC, mitomycin C; NLS, nuclear localization signal.

J. Clin. Invest.

(C) The American Society for Clinical Investigation, Inc.

0021-9738/96/05/2003/08 \$2.00

Volume 97, Number 9, May 1996, 2003-2010 result in part from the presence of at least five genetic complementation groups (6-8). Together this group of disorders represents the most frequent cause of inherited aplastic anemia and an important cause of childhood leukemia $(4,9)$.

Using an expression cloning strategy, the $F A C$ gene defective in FA complementation group C cells (FA-C) was isolated by virtue of its ability to suppress the cytotoxicity of cross-linkers (10). The human gene encodes a polypeptide of 558 amino acids with a molecular mass of $60 \mathrm{kD}$, which is identical at $65 \%$ of the residues to the murine homolog (11). FAC corrects both the cross-linker-induced cytotoxicity $(10,12,13)$ and chromosomal fragility $(14,15)$ of FA-C cells, and a variety of intragenic mutations $(10,16-19)$ that can presumably inactivate the function of the protein have been described. The ubiquitous expression of the gene, its conservation in evolution, and the phenotypic consequences of its deficiency point toward an important role in development. However, the precise physiological function of FAC has remained elusive.

Although the dual features of genomic instability and cancer susceptibility have raised the specter of an abnormality in DNA repair (20), the fundamental biochemical defect of FA has not yet been elucidated. Because of the increased susceptibility of FA cells to bifunctional alkylating agents relative to monofunctional ones, interstrand cross-linking of DNA is thought to contribute to the pathogenesis of FA (4). These lesions could interfere with progression of the replication fork and impart a cascade of deleterious effects on chromosome integrity, RNA and protein synthesis, and cell viability. The nucleotide excision pathway is most likely involved in the repair of such lesions. Included in this pathway are nuclear enzymes that can recognize and excise damaged DNA and fill in gaps by repair replication and ligation (21). A number of these enzymes also form integral components of the transcription initiation complex (22-25), and defects in this pathway can cause the related chromosomal instability syndrome xeroderma pigmentosum. While it is possible that similar defects could also account for the pathogenesis of some subsets of FA, several recent observations have made it difficult to implicate deficiencies of DNA repair in FA-C cells. In particular, the absence of a bona fide nuclear localization signal (NLS) in FAC $(26,27)$ and the recent demonstration that the protein localizes primarily to the cytoplasm of mammalian cells $(12,13,28)$ have cast doubt on a direct role in DNA repair. However, this possibility could not be precluded for at least two reasons: first, a small functional pool of FAC could remain in the nucleus but escape detection with the available immunological reagents; and second, the spatial location of FAC may be dictated by the physiological state of the cell.

The availability of $F A C$ cDNA has made it possible to analyze the turnover of interstrand cross-links in FA-C cells before and after complementation. In this study, it is demonstrated that the only competent forms of FAC that can rescue FA-C cells from the toxicity of cross-linkers are cytoplasmic, while a nuclear form is incompetent. Furthermore, the major 
molecular defect in FA-C cells precedes cross-link repair. The ability of FAC to impart resistance to FA-C cells reaches a threshold. These observations lead to a proposed cellular defense pathway for genotoxic agents in which FAC acts through a cytoplasmic compartment and at a proximal step within this pathway.

\section{Methods}

Cell culture. EBV-transformed human lymphoblastoid cell lines were maintained in RPMI 1640 (GIBCO BRL, Grand Island, NY) and $15 \%$ FCS. Nonlymphoblastoid cells were grown in Dulbecco's modified essential medium (DMEM) and 10\% FCS. Sera were heatinactivated before use. Cells were grown at $37^{\circ} \mathrm{C}$ in a humidified atmosphere containing $5 \% \mathrm{CO}_{2}$.

Construction and mutagenesis of FAC constructs. The isolation of a mammalian expression vector containing the $4.5-\mathrm{kb}$ full-length $F A C$ cDNA (called DRA-FAC; 13 ) in the expression vector DRA-CD (29) and construction of the NLS-FAC in the vector pcDNA1 (28) have been described previously. To generate the mutNLS-FAC construct, the pcDNA-NLS/FAC construct (28) was used as a template for amplifying a 356-bp fragment by using the PCR. The sequence of the 5' PCR primer (5'-CGC-GTC-GAC-AAG-ATG-CCA-AAAACG-AAG-AGA) was modified to result in the substitution of threonine for lysine at codon 128 (underlined) in the native Simian Virus 40 large $\mathrm{T}$ antigen NLS, PKKKKRKVD (30). The primer also included a methionine initiation codon and an artificial SalI site for subcloning. The 17-mer 3' PCR primer (5'-CCA-GAA-TTC-TGT-GGT-TC) corresponded to nucleotides 317-301 of the coding region of FAC (10). After sequencing to ensure the introduction of the desired substitution, the PCR fragment was digested with SalI and EcoRI and substituted for the corresponding wild-type fragment in DRA-FAC. For expression in COS- 1 cells, the FAC isoforms were also cloned in pED6 (gift of R. Wise, Brigham and Women's Hospital, Boston, MA).

Electroporation and selection of FA lymphoblasts. EBV-transformed human lymphoblastoid cells were transfected with FAC constructs cloned in DRA-CD by electroporation, as described previously (13). After $48 \mathrm{~h}$, viable cells were isolated by centrifugation over a cushion of Nycodenz (Nycomed Pharmaceuticals, Olso, Norway), the interface containing live cells was washed twice with RPMI, and the percentage of live cells was estimated by trypan blue staining. For rapid enrichment of transfected cells, the ability of DRA-CD to encode the human $\mathrm{T}$ cell surface antigen $\mathrm{CD} 4$ was exploited. Before incubation with the transfected cells, the anti-CD4 IOT4a mAb (AMAC Inc., Westbrook, ME) was bound to magnetic beads coupled to goat antimouse IgG (Advanced Magnetics, Cambridge, MA). Approximately $1-2 \times 10^{7}$ viable cells resuspended in $100 \mu \mathrm{l}$ RPMI were incubated with $40 \mu \mathrm{l}$ slurry $(80 \% \mathrm{vol} / \mathrm{vol})$ of immunomagnetic beads for $30 \mathrm{~min}$ and isolated by passage over a magnet. After incubation in complete medium for 4-16 h, aliquots were selected further in hygromycin B (Boehringer Mannheim Biochemicals, Indianapolis, IN) beginning at an initial dose of $125 \mu \mathrm{g} / \mathrm{ml}$ and increasing to $200 \mu \mathrm{g} / \mathrm{ml}$. After $2 \mathrm{wk}$, viable hygromycin-resistant cells were obtained by centrifugation over a Nycodenz cushion.

Denaturation-renaturation assay. To assess the induction of interstrand cross-links, cells were treated with a range of MMC concentrations (up to $10 \mu \mathrm{g} / \mathrm{ml}$ ) for $1 \mathrm{~h}$, and purified genomic DNA was analyzed by the denaturation-renaturation gel electrophoresis (DRGE) assay, as described previously (31-33). Briefly, high molecular weight genomic DNA prepared as described previously (34) was digested with SacI, extracted successively with buffered phenol and chloroform, and precipitated with ethanol. The DNA pellet was resuspended in $10 \mathrm{mM}$ Tris- $\mathrm{HCl}, 25 \mathrm{mM}$ EDTA, $\mathrm{pH} 8.0$, to a final concentration of $1 \mu \mathrm{g} / \mu \mathrm{l}$. In parallel, $5-\mu \mathrm{g}$ aliquots of DNA were electrophoresed either in their native forms or after denaturation with $0.2 \mathrm{~N} \mathrm{NaOH}$ at $55^{\circ} \mathrm{C}$ for $10 \mathrm{~min}$. To allow for the rapid renaturation of covalently cross-linked DNA, denatured samples were chilled briefly on ice before electrophoresis on $0.8 \%$ agarose gels in a buffer of $40 \mathrm{mM}$ Tris-phosphate $2 \mathrm{mM}$ EDTA, pH 8.0. DNA was transferred to Biotrans nylon membranes (ICN Biomedicals Inc., Irvine, CA), and a ${ }^{32} \mathrm{P}$-labeled 1.1-kb fragment of the $28 \mathrm{~S}$ human rRNA gene (35) was used to probe the blots. Under these conditions singlestranded DNA migrates at $2 \mathrm{~kb}$, while double-stranded DNA migrates at $9 \mathrm{~kb}$. For analysis of the repair of DNA cross-links, cells exposed to MMC for $1 \mathrm{~h}$ were washed twice with RPMI, resuspended in complete medium, and incubated in RPMI supplemented with $15 \%$ FBS. After 24 or $48 \mathrm{~h}$, viable cells were harvested over a Nycodenz cushion and analyzed by the DRGE assay. The latter step differed from previous protocols (31-33) by the omission of bromodeoxyuridine during the repair phase; instead, only viable cells obtained by Nycodenz centrifugation were analyzed. The absence of bromodeoxyuridine appeared to improve the digestion of DNA with SacI and yielded sharper band images on autoradiography. The intensity of radioactivity in the 9-kb band was assessed by PhosphorImaging, and the intensity in denatured samples relative to their counterparts in nondenatured samples was taken to reflect the degree of covalent interstrand cross-linking.

Transfection and immunofluorescence microscopy. COS-1 cells were grown to $\sim 50 \%$ confluence in 10 -cm dishes containing DMEM- $10 \%$ heat-inactivated calf serum. Plasmid DNA was resuspended to a final concentration of $1 \mu \mathrm{g} / \mathrm{ml}$ in $4 \mathrm{ml}$ of DMEM-10\% newborn calf serum and containing $400 \mu \mathrm{g} / \mathrm{ml}$ of DEAE-dextran and $100 \mu \mathrm{M}$ chloroquine diphosphate. $16 \mathrm{~h}$ after transfection cells were detached with trypsin and replated on sterile glass coverslips. $3 \mathrm{~d}$ after transfection cells were washed twice in PBS, $1 \%$ BSA, fixed in $3.5 \%$ paraformaldehyde, and incubated sequentially with an affinity-purified polyclonal antiserum raised against a recombinant fusion protein encoding glutathione $S$-transferase at the amino terminus and FAC (amino acids 6 to 558) at the carboxy terminus, as described previously $(13,28)$ and fluorescein-conjugated goat anti-rabbit IgG (Cappel Laboratories, West Chester, PA).

Metabolic labeling and immunoprecipitation. Cells were metabolically labeled with Expre ${ }^{35} \mathrm{~S}^{35} \mathrm{~S}$ label $(0.2 \mathrm{mCi} / \mathrm{ml}$; DuPont, Wilmington, DE) for $1 \mathrm{~h}$ in cysteine- and methionine-deficient DMEM. Cell pellets were washed with PBS and lysed in a buffer containing 20 $\mathrm{mM}$ Tris, $\mathrm{pH} 8.0,50 \mathrm{mM} \mathrm{NaCl}, 0.5 \%$ deoxycholate, $1 \% \mathrm{NP}-40$ and a cocktail of protease inhibitors. The postnuclear supernatant was incubated with anti-FAC antibody for $16 \mathrm{~h}$ at $4{ }^{\circ} \mathrm{C}$, followed by immunoprecipitation of the immunocomplexes with protein A-agarose beads for $2 \mathrm{~h}$ (Bio-Rad Laboratories, Richmond, CA). The unbound supernatant was subjected to a second round of immunoprecipitation to maximize the recovery of the antigen. The combined immunocomplexes were washed three times with NET-gel buffer (34), boiled in $1 \times$ Laemmli buffer in the presence of $100 \mathrm{mM}$ dithiothreitol, and analyzed by denaturing $10 \%$ SDS-PAGE and autoradiography.

Determination of cell survival and doubling time. Cell survival in response to DEB (Aldrich Chemical Co., Milwaukee, WI) was performed by incubation of $10^{4}$ viable cells with different concentrations of DEB for $4 \mathrm{~d}$ and counting by trypan blue exclusion. The dose of DEB required to reduce the cell viability to $50 \%$ of control levels (EC50) was derived from cytotoxicity curves. Each experiment was performed at least in triplicate. For the measurements of doubling times, $10^{4}$ viable cells were plated within $24 \mathrm{~h}$ of transfection, and the cell number was determined after $48 \mathrm{~h}$ of growth in complete medium in the presence or absence of MMC.

\section{Results}

Subcellular targeting of FAC constructs. To evaluate the effect of the subcellular milieu on the function of FAC, a series of constructs were generated in mammalian expression vectors that would allow the forced targeting of FAC to the cytoplasm or the nucleus (Fig. $1 A$ ). A previous transient expression 
study showed that the placement of a heterologous NLS at the amino-terminal region of FAC directed the chimeric protein to the nuclei of transfected COS cells (28). The NLS-FAC construct contains the minimal NLS of the Simian Virus 40 large $\mathrm{T}$ antigen at the amino terminus of FAC. MutNLS-FAC differs from NLS-FAC by the substitution of a threonine residue for lysine at the third position of the minimal NLS; this mutation has been shown previously to abolish nuclear localization (30). The efficiency of transfection of COS- 1 cells was $\sim 30 \%$, and for each transfected construct 100 fluorescent cells were counted to assess the subcellular localization of the exogenous FAC protein. Transfection with wild-type FAC or mutNLSFAC and incubation of permeabilized cells with anti-FAC antibody showed a cytoplasmic pattern in virtually all positive cells, while the expression of NLS-FAC showed localization to nuclei in $>95 \%$ of positive cells (Fig. $1 \mathrm{~B}$ ), and both nuclear and variable degrees of cytoplasmic staining in the remainder. The localization of these constructs by indirect immunofluorescence in three different FA-C lymphoblastoid cell lines was similar to that in COS-1 cells, although the small size of lymphoblastoid cells and the greater background staining partially obscured these differences (Table I; data not shown).

Correction of cytotoxicity by cytoplasmic isoforms. The ability of FAC to correct the hypersensitivity of FA-C cells to cross-linkers was assayed in three lymphoblastoid cell lines containing different $F A C$ mutations. These cells were also chosen for their comparable and relatively rapid rates of growth (Table II). The GM4510 cells are homozygous for the IVS-4 mutation in the FAC gene (17). We have previously demon- strated that these cells are hypersensitive to cross-linkerinduced cytotoxicity and can be complemented with FAC constructs (13). After electroporation with DRA-CD-based vectors (29), cells were subjected to a single round of selection for surface CD4 expression, followed by growth in different concentrations of DEB for $4 \mathrm{~d}$. As expected, FAC expression corrected the hypersensitivity of GM4510 cells to DEB-induced cytotoxicity (Table I). The degree of correction was comparable to the DEB sensitivity of non-FA cells or to FA-C cells complemented with wild-type FAC, as observed previously (7, 10). By contrast, there was no significant correction of cytotoxicity in cells transfected with either the control DRA-CD plasmid or with NLS-FAC. However, mutNLS-FAC restored the intracellular activity of FAC and corrected the DEB-induced cytotoxicity. The expression of these isoforms in two other FA-C cell lines $(10,18)$ yielded very similar results (Table I). To exclude a generalized toxic effect of NLS-FAC or, conversely, a growth advantage for the cytoplasmic isoforms that might account for the discrepancy, the doubling times of transfected FA-C cells were measured within $24 \mathrm{~h}$ of surface CD4 selection. As no significant differences were noted in the doubling times (Table II), such effects are unlikely to explain the lack of competence of the nuclear isoform. These results demonstrate that the cytoplasmic location of FAC is essential for its ability to ameliorate cross-linker-induced cytotoxicity of FA-C cells.

Regulated levels of FAC. The modulation of cross-linker toxicity by FAC may be a direct function of its intracellular level. Alternatively, FAC could work either indirectly or

A


128



B

FAC

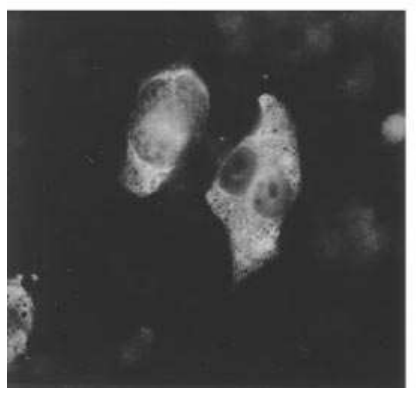

NLS-FAC



mutNLS-FAC

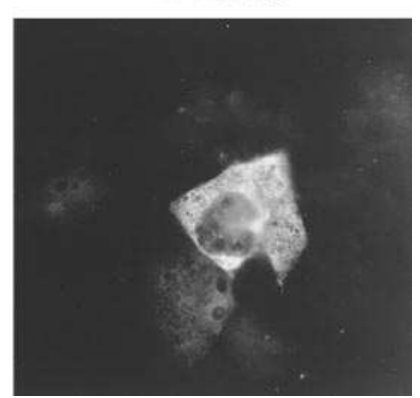

Figure 1. Subcellular targeting of FAC. (A) Schematic representation of FAC constructs. The open region corresponding to wild-type FAC is identical in all three constructs. The positions of the wild-type or mutant Simian Virus 40 large $T$ antigen NLS, the coding frame at the aminoterminal junction, and a one amino acid linker (parentheses) are shown. (B) Immunofluorescence analysis of FAC isoforms. COS-7 cells transfected with FAC, NLS-FAC, or mutNLS-FAC cloned in the vector pED6. $48 \mathrm{~h}$ after transfection, cells were fixed with $3.5 \%$ paraformaldehyde, permeabilized in PBS and $0.1 \%$ triton $\mathrm{X}-100$, and incubated sequentially with anti-FAC antibody and FITC-conjugated goat anti-rabbit IgG. Photomicrographs of representative cells were taken at a magnification of $\times 40$. 


\begin{tabular}{|c|c|c|c|c|c|}
\hline \multirow[b]{2}{*}{ Cell line } & \multirow[b]{2}{*}{ FAC mutation } & \multirow[b]{2}{*}{ Transgene } & \multirow[b]{2}{*}{ Localization } & \multicolumn{2}{|c|}{ DEB EC50 (nM)* } \\
\hline & & & & $\mathrm{LO}^{\ddagger}$ & $\mathrm{HI}^{\S}$ \\
\hline GM4510 & IVS4/IVS4 & Mock $^{\|}$ & - & $135 \pm 15$ & $85 \pm 10$ \\
\hline GM4510 & IVS4/IVS4 & FAC & $\mathrm{Cyt}^{\mathrm{q}}$ & $1,300 \pm 50$ & $1,400 \pm 30$ \\
\hline GM4510 & IVS4/IVS4 & NLS-FAC & Nuc** & $30 \pm 5$ & $\mathrm{ND}^{\ddagger \ddagger}$ \\
\hline GM4510 & IVS4/IVS4 & mutNLS-FAC & Cyt & $1,500 \pm 75$ & ND \\
\hline HSC536 & L554P/? & Mock & $\pm \mathrm{Cyt}^{\S \S}$ & $50 \pm 10$ & $70 \pm 20$ \\
\hline HSC536 & $\mathrm{L} 554 \mathrm{P} / ?$ & FAC & Cyt & $1,650 \pm 100$ & $1,800 \pm 50$ \\
\hline HSC536 & $\mathrm{L} 554 \mathrm{P} / ?$ & NLS-FAC & Nuc & $20 \pm 5$ & ND \\
\hline HSC536 & $\mathrm{L} 554 \mathrm{P} / ?$ & mutNLS-FAC & Cyt & $1,400 \pm 200$ & ND \\
\hline RA568 & 332DG/R185X & Mock & - & $85 \pm 10$ & $15 \pm 1$ \\
\hline RA568 & 332DG/R185X & FAC & Cyt & $2,000 \pm 400$ & $1,800 \pm 50$ \\
\hline RA568 & 332DG/R185X & NLS-FAC & Nuc & $120 \pm 50$ & ND \\
\hline RA568 & 332DG/R185X & mutNLS-FAC & Cyt & $1,400 \pm 150$ & ND \\
\hline
\end{tabular}

*Concentration of DEB required to reduce the cell viability to $50 \%$ of control values expressed as mean \pm SD. ${ }^{\circ} \mathrm{LO}$, transfected cells enriched by immunoselection and expressing low levels of FAC (relative to hygromycin-resistant cells). ${ }^{\S} \mathrm{HI}$, transfected cells obtained by dual immunoselection and resistance to hygromycin B and expressing higher levels of FAC (relative to cells obtained by immunoselection alone). Mock, transfection with DRA-CD. ${ }^{\mathbb{T}}$ Cyt, cytoplasmic localization as determined by indirect immunofluorescence. ${ }^{* * N u c}$, nuclear localization as determined by indirect immunofluorescence. ${ }^{\ddagger}$ Not determined. ${ }^{\S \S}$ Low background reactivity by indirect immunofluorescence most likely reflecting expression of endogenous mutant (L554P) FAC allele.

through associations with accessory proteins, whereby the rate-limiting step may be independent of its level and determined instead by other factors. The ability to manipulate the intracellular levels of FAC could distinguish between these two models. To generate cells that express different levels of FAC, advantage was taken of the dual selection scheme of DRA-CD, and the expression of FAC was compared in pairs of FA-C cells selected either solely for surface CD4 expression or additionally for resistance to hygromycin B. CD4-selected cells expressed low levels of FAC as assessed by metabolic labeling and quantitative immunoprecipitation (Fig. 2). In our experience, these levels are roughly comparable to the low levels of wild-type FAC in non-FA-C cells. By contrast, the expression of FAC in hygromycin-resistant cells was induced at least fourfold as compared to CD4-selected cells (Fig. 2). Preimmune antisera failed to show the 60-kD FAC band (data not shown). Although the hypersensitivity of all three FA-C cell lines to DEB-induced cytotoxicity was corrected to normal levels by either low or high levels of FAC expression (Table I), the degree of correction was no greater in cells expressing higher levels of FAC protein than in their counterparts expressing lower levels. These data demonstrate that the correc-

Table II. Growth Rates of FA-C Cells

\begin{tabular}{|c|c|c|c|c|c|}
\hline \multirow[b]{2}{*}{ Cell line } & \multirow[b]{2}{*}{ Transgene ${ }^{\ddagger}$} & \multirow[b]{2}{*}{ No MMC } & \multicolumn{3}{|c|}{ Doubling time (h)* } \\
\hline & & & MMC & $\mathrm{MMC}$ & $\mathrm{MMC}$ \\
\hline & & & $0.1 \mu \mathrm{g} / \mathrm{ml}$ & $1 \mu g / m l$ & $10 \mu g / m l$ \\
\hline GM4510 & Mock & 20.4 & 20.7 & 22.3 & 34.0 \\
\hline GM4510 & FAC & 21.3 & 20.5 & 22.3 & 32.9 \\
\hline GM4510 & NLS-FAC & 22.0 & ND & ND & ND \\
\hline GM4510 & mutNLS-FAC & 20.9 & ND & ND & ND \\
\hline HSC536 & Mock & 23.2 & 21.0 & 22.6 & 36.0 \\
\hline HSC536 & FAC & 22.0 & 20.9 & 22.5 & 34.5 \\
\hline HSC536 & NLS-FAC & 23.0 & ND & ND & ND \\
\hline HSC536 & mutNLS-FAC & 22.0 & ND & ND & ND \\
\hline RA568 & Mock & 22.1 & 21.4 & 22.7 & 29.8 \\
\hline RA568 & FAC & 20.6 & 19.8 & 23.0 & 31.0 \\
\hline RA568 & NLS-FAC & 20.5 & ND & ND & ND \\
\hline RA568 & mutNLS-FAC & 21.8 & ND & ND & ND \\
\hline
\end{tabular}

*Doubling times were assessed by growth of $1 \times 10^{4}$ cells in multititer well plates in 1 ml volumes and trypan blue exclusion after 48 h. Exposure to MMC was for $1 \mathrm{~h}$. The mean values of three independent experiments are shown. ${ }^{\ddagger}$ Cells were transfected with either DRA-CD (mock) or FAC-containing DRA-based vectors, selected for surface CD4 expression, and assayed within $24 \mathrm{~h}$ of selection. ND, not determined. 


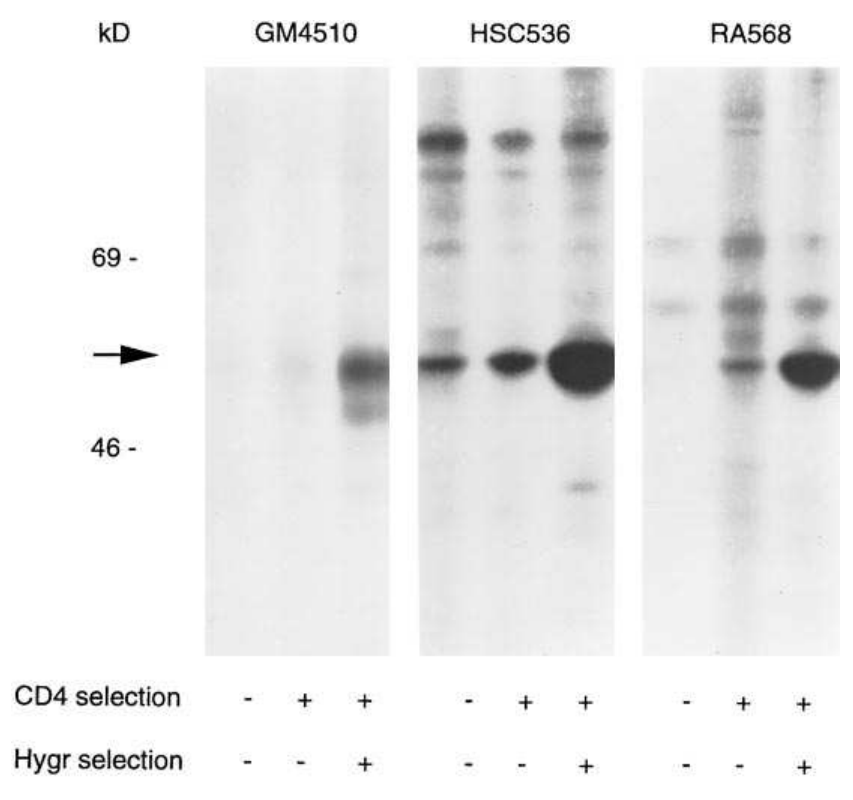

Figure 2. Immunoprecipitation of FAC from transfected cells. FA-C lymphoblastoid cells transfected with either DRA-CD (left lanes) or DRA-FAC (center lanes and right lanes) by electroporation were subjected to one round of selection for surface CD4 expression or selected further in hygromycin B (hygr), as indicated. Cells were metabolically labeled for $1 \mathrm{~h}$, and cytosolic extracts were immunoprecipitated successively with polyclonal anti-FAC antibody and protein A-agarose. Immunocomplexes were analyzed by SDS-PAGE. The position of FAC is shown (arrow). Variable cross-reacting bands can be frequently detected in immunocomplexes of radiolabeled lymphoblasts, but not in nonlymphoblastoid cells (data not shown).

tion of cross-linker-induced cytotoxicity reaches a threshold despite increasing intracellular levels of FAC.

Defective induction of interstrand cross-links. To elucidate the role of FAC in the regulation of DNA cross-linking, the "denaturation-renaturation gel electrophoresis" assay (DRGE; 31-33) was used to quantitate the induction and repair of interstrand cross-links in transfected FA-C cells. After a brief exposure to $\mathrm{MMC}$, the accumulation of genomic interstrand crosslinks in these cells was assessed by the relative resistance of the $28 \mathrm{~S}$ rRNA gene to alkaline denaturation. Fully denatured single-stranded DNA migrates at $2 \mathrm{~kb}$, while cross-linked doublestranded DNA migrates at $9 \mathrm{~kb}$. Thus, the proportion of radiolabel in the 9-kb band in alkali-denatured samples reflects the degree of covalent interstrand cross-linking. Preliminary experiments partially confirmed previously described studies on the dose-response relationship of MMC $(32,33)$ that the formation of interstrand cross-links is a linear function of the dose of MMC in the range $0.1-3 \mu \mathrm{g} / \mathrm{ml}$ in non-FA lymphoblasts, HL60 and 293 cells (data not shown). However, in the present study the linearity was lost at higher doses and cell viability decreased significantly (Table II). Hence, doses of cross-linkers that did not perturb the cell doubling times were chosen for further analysis. In GM4510 cells transfected with DRA-CD, the induction of interstrand cross-links was readily apparent after exposure to MMC of $0.1 \mu \mathrm{g} / \mathrm{ml}$ for $1 \mathrm{~h}$ (Fig. 3). By contrast, significantly higher doses of MMC were required to generate equivalent amounts of cross-linked DNA in FACcomplemented cells as judged by the intensity of the 9-kb double-stranded band. Moreover, no significant differences were

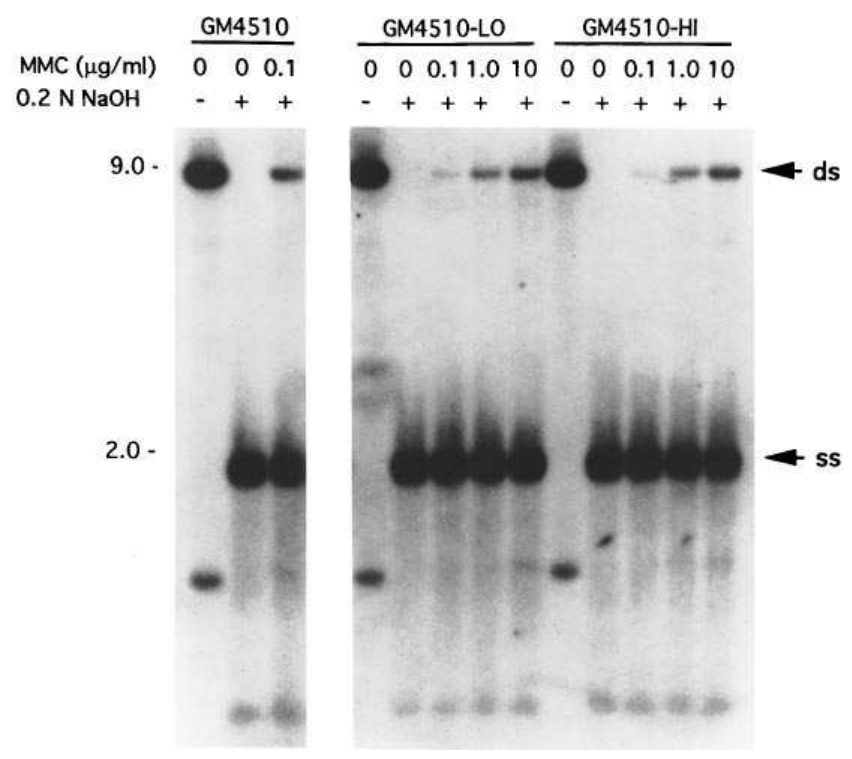

Figure 3. Susceptibility of FA-C cells to cross-linking. The DRGE assay was used to quantitate the induction of interstrand cross-links in GM4510 cells transfected with DRA-CD (mock) or DRA-FAC selected either for surface $\mathrm{CD} 4$ expression $(L O)$ or for resistance to hygromycin B $(H I)$. After exposure to MMC for $1 \mathrm{~h}$, genomic DNA was isolated, cleaved with SacI, and similar aliquots electrophoresed on agarose gels before or after denaturation with $\mathrm{NaOH}$. Southern blots were hybridized with a ${ }^{32} \mathrm{P}$-labeled 1.1-kb BamHI fragment of the $28 \mathrm{~S}$ human rRNA gene (35). The positions of single-stranded (ss) and double-stranded DNA $(d s)$ are shown.

noted between low- and high-expressing cells. The dose of MMC required to generate cross-linked DNA in FACcomplemented GM4510 cells was comparable to that observed in non-FA lymphoblasts, HL60, and 293 cells (data not shown). Similar results were also obtained with HSC536 and RA568 cells transfected with DRA-FAC (Fig. 4). These results demonstrate that FA-C cells are profoundly sensitive to interstrand DNA cross-linking induced by MMC, which is corrected completely by complementation with low levels of wildtype FAC.

FA-C cells transfected with either NLS-FAC or mutNLSFAC and selected for surface CD4 expression were also analyzed by the DRGE assay. Because a dose of $0.1 \mu \mathrm{g} / \mathrm{ml} \mathrm{MMC}$ was discriminatory (Fig. 3), cells transfected with different isoforms of FAC were compared by DRGE after exposure to 0.1 $\mu \mathrm{g} / \mathrm{ml} \mathrm{MMC} \mathrm{for} 1 \mathrm{~h}$. While NLS-FAC failed to correct the cross-linking defect in these cells, mutNLS-FAC corrected the defect in all three cell lines to about the same degree as wildtype FAC (Fig. 4). These results demonstrate that the cytoplasmic location of FAC is also necessary for the correction of the interstrand cross-linking defect induced by MMC.

To investigate the efficiency of interstrand cross-link repair, mock- and FAC-transfected cells were treated with different doses of MMC for $1 \mathrm{~h}$ before repair to obtain similar levels of initial cross-link damage. Cells were subsequently allowed to incubate in MMC-free media, and the level of interstrand DNA cross-linking assessed by DRGE after 24 and $48 \mathrm{~h}$. In GM4510 cells, there were no significant differences in the rate of interstrand cross-link repair between vector- or FAC-transfected cells (Fig. 5). The efficiency of repair in these 


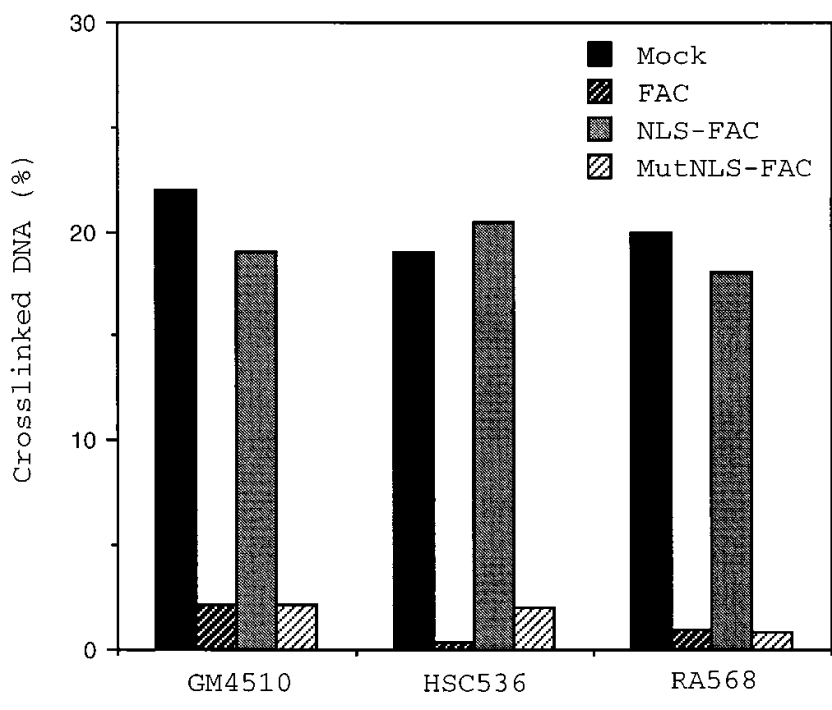

Figure 4. Effect of FAC isoforms on the correction of the cross-linking defect. FA-C cells transfected with DRA-CD-based vectors and selected for surface CD4 expression were analyzed by DRGE after treatment with $0.1 \mu \mathrm{g} / \mathrm{ml} \mathrm{MMC} \mathrm{for} 1 \mathrm{~h}$. Shown are the relative intensities of the 9-kb SacI fragment in alkali-denatured samples, normalized to nondenatured double-stranded DNA (100\%). Intensities of the double-stranded 9-kb band were determined by PhosphorImaging. Values represent the results of one representative experiment. FAC constructs are shown in key. Mock, transfection with DRA-CD.

cells was also comparable to the repair rates in non-FA lymphoblastoid cells as well as HL60 and 293 cells (data not shown). Similarly, there were no deficiencies in the repair of MMC-induced cross-links in HSC536 and RA568 cells transfected with DRA-CD, and complementation with FAC caused no further detectable changes in the rates of repair (data not shown). These results demonstrate that the rate of MMCinduced cross-link repair in FA-C cells is comparable to nonFA cells and is not affected by wild-type FAC expression.

\section{Discussion}

Based on the cellular and chromosomal aberrations of FA (1-5), it would be reasonable to suggest that a pathway dedicated to the maintenance of genomic stability but vulnerable to cross-linkers is deficient in FA. The fundamental biochemical mechanism responsible for cross-linker hypersensitivity, however, has remained controversial. Whereas deficient removal of cross-link adducts from cellular DNA was noted in some studies $(32,36,37)$, other studies using different cell lines failed to demonstrate such a relationship $(33,38,39)$. Some of this discrepancy may have resulted from the wide genetic heterogeneity of FA that has been appreciated more recently (6$8)$. However, even within defined complementation groups and clonal cell lines, the intrinsic genetic instability of FA and the possibility of acquiring additional mutations with progressive cell divisions might result in unexpected phenotypic changes that could limit the power of such studies. The ability to complement putative repair-deficient cells and attempt to correct the defective phenotype can obviate those pitfalls. Using this strategy, the present data demonstrate that FAC works through a cytoplasmic compartment(s) to regulate a biochemi-

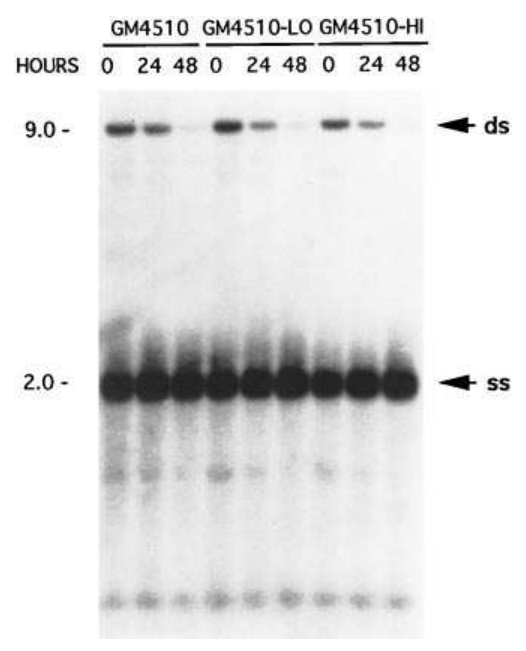

Figure 5. Normal rates of cross-link repair in FA-C cells. Transfected cells were selected either for surface CD4 expression $(L O)$ or for resistance to hygromycin $\mathrm{B}(H I)$, as described in Methods. The DRGE assay was used to assess the efficiency of interstrand cross-link repair in transfected GM4510 cells after exposure to $0.3 \mu \mathrm{g} / \mathrm{ml}$ (for DRA-CD-transfected cells) or $3 \mu \mathrm{g} / \mathrm{ml}$ (for DRA-FAC-trans-

fected cells) of MMC for $1 \mathrm{~h}$. Cells were then allowed to incubate in MMC-free media, and the level of interstrand cross-linking was assessed after 24 and $48 \mathrm{~h}$ by Southern blotting of SacI-digested, alkalidenatured DNA. The probe was a 1.1-kb BamHI fragment of the $28 \mathrm{~S}$ human rRNA gene (35). The positions of single-stranded (ss) and double-stranded DNA $(d s)$ are shown.

cal step that precedes the repair of interstrand cross-links. In this sense, the prerepair step represents a proximal function within this pathway, which is regulated by FAC.

Two aspects of this analysis should be viewed with caution. First, it is possible that the assessment of interstrand cross-linking within the rRNA gene complex may not be an accurate reflection of a general susceptibility of the whole genome to cross-linker-induced toxicity. While the detection of interstrand cross-links in the DRGE assay is clearly enhanced with the use of probes for the highly repetitive rRNA genes, the transcriptional activity of those genes and perhaps their spatial location within "nucleolar organizer regions" could render them particularly susceptible to such lesions by facilitating access to cross-linkers (40). Thus, it is possible that other regions in the nuclear chromatin have different degrees of susceptibility to cross-linkers. Second, it is also conceivable that crosslinkers could target macromolecules other than DNA, which in turn can contribute to the pathogenesis of FA. In this light, the modulation of interstrand cross-links within the rRNA gene locus is best viewed as an analytical target rather than as a critical pathogenetic target in FA.

The prerepair defect characterized in this study may be unique to FA-C cells and not shared by other FA complementation groups. Although these groups are related to each other by their overall clinical features and hypersensitivity to crosslinkers, whether or not they also share fundamental biochemical defects is presently unknown. In FA-A cells, an abnormality in a damage recognition protein involved in the initial incision step of the nucleotide excision pathway has been demonstrated (41). This intriguing observation coupled with earlier studies implicating repair defects in FA-A cells suggests that the FA phenotype could result from deficiencies of a number of distinct biochemical pathways, at least with respect to FA-A and FA-C. However, until the remaining FA genes are cloned and the molecular function of their protein products understood, the biochemical relationship among the different complementation groups will remain uncertain. 
While necessarily speculative, one attractive possibility for the function of FAC might be as a "sensor" for a specific class of genotoxic agents. Consistent with this model are the subcellular location of FAC, the critical dependence of its intracellular function on correct cytoplasmic localization, and the prerepair defect of FA-C cells that leads to a higher degree of permissiveness for interstrand DNA cross-links. However, another possibility is that FAC is an "effector" (e.g., an enzyme involved in the catabolism of genotoxic agents). Although the present data cannot distinguish between these two models, the lack of induction in the level of FAC under a variety of conditions (42; data not shown) and the threshold effect seen in this study lend some support to the sensor model. If it is assumed that the effectors responsible for the rate-limiting effect are located downstream of FAC, it may be predicted that their overexpression would lead to a greater degree of cellular resistance to cross-linkers. There are other possible explanations for the threshold effect. For example, the function of FAC may be regulated by an interaction with accessory proteins (13), and the relative levels of these proteins could establish the ratelimiting effect. A priori, these proteins could constitute part of the sensory or the effector arm of this hypothetical organization.

A number of elegant mechanisms exist for the subcellular targeting of proteins. Although NLS motifs are frequently required for protein targeting to the nucleus $(26,27)$, it has become increasingly clear that alternative mechanisms also exist for nuclear transport. One mechanism for nuclear entry of smaller proteins is by passive diffusion. For example, the product of the XPAC gene defective in xeroderma pigmentosum complementation group A contains both a NLS located in exon 1 of the gene as well as a zinc finger motif. Deletion of the NLS showed that it was not essential for the activity of the protein (43). This surprising result was thought to be due to passive diffusion of the relatively small $(\sim 31 \mathrm{kD})$ deletion mutant into the nucleus. In the case of FAC, both the large size of the wild-type protein and the forced nuclear targeting of a chimeric protein argue strongly that its biological activity is mediated through a cytoplasmic compartment. A second mechanism is by "piggyback transport" with other proteins that are destined for the nucleus. This is achieved through protein-protein interactions, and examples include the adenovirus-encoded DNA polymerase (44) and a pancreatic transcription factor (45). The identification of a novel glycine-rich targeting motif in the heterogeneous nuclear ribonucleoprotein represents yet another specific mechanism for nuclear transport (46). The latter motif is not present in FAC (Youssoufian, H., personal observation). Conversely, nuclear trafficking can also be effected by the presence of specific nuclear export mechanisms that may use short hydrophobic signals (47, 48); such motifs are also absent from FAC (Youssoufian, H., personal observation). The strategy of forced subcellular targeting used in this study may be an efficient way to correlate the intracellular function of a protein with its physical localization in specific subcellular compartments, and it may be extended to other proteins involved in chromosomal instability syndromes whose function is currently uncertain (49).

The present results may have implications for the clinical efficacy of certain chemotherapeutic agents. The threshold effect suggests that selective overexpression of FAC in nonmalignant cells is not likely to protect them from the cytotoxicity of cross-linkers. Alternatively, a novel strategy to enhance the efficacy of cross-linkers in tumor cells may be achieved through the forced direction of FAC to the nucleus - perhaps through appropriate piggyback carriers - which could sensitize these cells to the cytotoxic properties of such agents.

\section{Acknowledgments}

I wish to thank Hans Joenje, Youlin Li, and Jiongru Wu for stimulating discussions, Hans Joenje (Free University of Amsterdam, Amsterdam, The Netherlands) for contributing a sample of the HSC536 cell line (obtained from Manuel Buchwald), Arleen Auerbach (The Rockefeller University, New York) for the RA568 cell line, and Viktor Steimle (University of Geneva, Geneva, Switzerland) for the DRA-CD vector.

This study was supported by grants from the National Institutes of Health (HL52138) and the Aplastic Anemia Foundation of America.

\section{References}

1. Fanconi, G. 1967. Familial panmyelocytopathy, Fanconi's anemia (FA). I. Clinical aspects. Semin. Hematol. 4:233-240.

2. Glanz, A., and F.C. Fraser. 1982. Spectrum of anomalies in Fanconi anaemia. J. Med. Genet. 19:412-416.

3. Giampietro, P.F., B. Adler-Brecher, P.C. Verlander, S.G. Pavlakis, J.G. Davis, and A.D. Auerbach. 1993. The need for more accurate and timely diagnosis in Fanconi anemia: a report from the International Fanconi Anemia Registry. Pediatrics. 91:1116-1120.

4. Liu, J.M., M. Buchwald, C.E. Walsh, and N.S. Young. 1994. Fanconi anemia and novel strategies for therapy. Blood. 84:3995-4007.

5. Auerbach, A.D., A. Rogatko, and T.M. Schroeder-Kurth. 1989. International Fanconi anemia registry: relation of clinical symptoms to diepoxybutane sensitivity. Blood. 73:391-396.

6. Duckworth-Rysiecki, G., K. Cornish, C.A. Clarke, and M. Buchwald. 1985. Identification of two complementation groups in Fanconi anemia. Somatic Cell Mol. Genet. 11:35-41.

7. Strathdee, C.A., A.M.V. Duncan, and M. Buchwald. 1992. Evidence for at least four Fanconi anaemia genes including FACC on chromosome 9. Nat. Genet. 1:196-198.

8. Joenje, H., J.R. Lo Ten Foe, A.B. Oostra, C.G.M. van Berkel, M.A. Rooimans, T. Schroeder-Kurth, R.-D. Wegner, J.J.P. Gille, M. Buchwald, and F. Arwert. 1995. Classification of Fanconi anemia patients by complementation analysis: evidence for a fifth genetic subtype. Blood. 86:2156-2160.

9. Auerbach, A.D., and R.G. Allen. 1991. Leukemia and preleukemia in Fanconi anemia patients: a review of the literature and report of the International Fanconi Anemia Registry. Cancer Genet. Cytogenet. 51:1-12.

10. Strathdee, C.A., H. Gavish, W.R. Shannon, and M. Buchwald. 1992. Cloning of cDNAs for Fanconi's anaemia by functional complementation. $\mathrm{Na}$ ture (Lond.). 356:763-767.

11. Wevrick, R., C.A. Clarke, and M. Buchwald. 1993. Cloning and analysis of the murine Fanconi anemia group C cDNA. Hum. Mol. Genet. 2:655-662.

12. Yamashita, T., D.L. Barber, Y. Zhu, N. Wu, and A.D. D'Andrea. 1994 The Fanconi anemia polypeptide FACC is localized to the cytoplasm. Proc. Natl. Acad. Sci. USA. 91:6712-6716.

13. Youssoufian, H., A.D. Auerbach, P.C. Verlander, V.Steimle, and B. Mach. 1995. Identification of cytosolic proteins that bind to the Fanconi anemia complementation group C polypeptide in vitro: evidence for a multimeric complex. J. Biol. Chem. 270:9876-9882.

14. Walsh, C.E., M. Grompe, E. Vanin, M. Buchwald, N.S. Young, A.W. Nienhuis, and J.M. Liu. 1994. A functionally active retrovirus vector for gene therapy in Fanconi anemia group C. Blood. 84:453-459.

15. Walsh, C.E., A.W. Nienhuis, R.J. Samulski, M.G. Brown, J.L. Miller, N.S. Young, and J.M. Liu. 1994. Phenotypic correction of Fanconi anemia in human hematopoietic cells with a recombinant adeno-associated virus vector. $J$. Clin. Invest. 94:1440-1448.

16. Murer-Orlando, M., J.C. Lierena, Jr., F. Birjandi, R.A. Gibson, and C.G. Mathew. 1993. FACC gene mutations and early prenatal diagnosis of Fanconi's anaemia. Lancet. 342:686.

17. Whitney, M.A., H. Saito, P.M. Jakobs, R.A. Gibson, R.E. Moses, and M. Grompe. 1993. A common mutation in the FACC gene causes Fanconi anaemia in Ashkenazi Jews. Nat. Genet. 4:202-205.

18. Verlander, P.C., J.D. Lin, M.U. Udono, Q. Zhang, R.A. Gibson, C.G. Mathew, and A.D. Auerbach. 1994. Mutation analysis of the Fanconi anemia gene FACC. Am. J. Hum. Genet. 54:595-601.

19. Gibson, R.A., A. Hajianpour, M. Murer-Orlando, M. Buchwald, and C.G. Mathew. 1993. A nonsense mutation and exon skipping in the Fanconi anaemia group C gene. Hum. Mol. Genet. 2:797-799. 
20. Setlow, R.B. 1978. Repair deficient human disorders and cancer. Nature (Lond.). 271:713-717.

21. Barnes, D.E., T. Lindahl, and B. Sedgwick. 1993. DNA repair. Curr. Opin. Cell Biol. 5:424-433.

22. Buratowski, S. 1993. DNA repair and transcription: the helicase connection. Science (Wash. DC). 260:37-38.

23. Feaver, W.J., J.Q. Svejstrup, L. Bardwell, A.J. Bardwell, S. Buratowski, K.D. Gulyas, T.F. Donahue, E.C. Friedberg, and R.D. Kornberg. 1993. Dual roles of a multiprotein complex from S. cerevisiae in transcription and DNA repair. Cell. 75:1379-1387.

24. Schaeffer, L., R. Roy, S. Humbert, V. Moncollin, W. Vermeulen, J.H. Hoeijmakers, P. Chambon, and J.M. Egly. 1993. DNA repair helicase: a component of BTF2 (TFIIH) basic transcription factor. Science (Wash. DC). 260:5863.

25.Cleaver, J.E. 1994. It was a very good year for DNA repair. Cell. 76:1-4.

26. Dingwall, C., and R.A. Laskey. 1991. Nuclear targeting sequences: a consensus? Trends Biochem. Sci. 16:478-481.

27. Robbins, J., S.M. Dilworth, R.A. Laskey, and C. Dingwall. 1991. Two interdependent basic domains in nucleoplasmin nuclear targeting sequence: identification of a class of bipartite nuclear targeting sequence. Cell. 64:615623.

28. Youssoufian, H. 1994. Localization of Fanconi anemia C protein to the cytoplasm of mammalian cells. Proc. Natl. Acad. Sci. USA. 91:7975-7979.

29. Steimle, V., L.A. Otten, M. Zufferey, and B. Mach. 1993. Complementation cloning of an MHC class II transactivator mutated in hereditary MHC class II deficiency (or bare lymphocyte syndrome). Cell. 75:135-146.

30. Kalderon, D., W.D. Richardson, A.T. Markham, and A.E. Smith. 1984. Sequence requirements for nuclear location of simian virus 40 large $\mathrm{T}$ antigen. Nature (Lond.). 311:33-38

31. Vos, J.-M., and P.C. Hanawalt. 1987. Processing of psoralen adducts in an active human gene: repair and replication of DNA containing monoadducts and interstrand cross-links. Cell. 50:789-799.

32. Matsumoto, A., J.-M.H. Vos, and P.C. Hanawalt. 1989. Repair analysis of mitomycin C-induced DNA cross-linking in ribosomal RNA genes in lymphoblastoid cells from Fanconi's anemia patients. Mutat. Res. 217:185-192

33. Rey, J.-P., R. Scott, and H. Muller. 1993. Induction and removal of interstrand cross-links in the ribosomal RNA genes of lymphoblastoid cell lines from patients with Fanconi anemia. Mutat. Res. 289:171-180.

34. Sambrook, J., E.F. Fritsch, and T. Maniatis. 1989. Molecular Cloning: A Laboratory Manual, Second Edition. Cold Spring Harbor Press, Cold Spring Harbor, NY

35. Gonzalez, I.L., J.L. Gorski, T.J. Campen, D.J. Dorney, J.M. Erickson, J.E. Sylvester, and R.D. Schmickel. 1985. Variation among human 28 S riboso- mal RNA genes. Proc. Natl. Acad. Sci. USA. 82:7666-7670.

36. Fujiwara, Y. 1982. Defective repair of mitomycin C cross-links in Fanconi's anaemia and loss in confluent normal and Xeroderma pigmentosum cells. Biochem. Biophys. Acta. 699:635-649.

37. Papadopoulo, D., D. Averbeck, and E. Moustacchi. 1987. The fate of 8-methoxypsoralen-photoinduced DNA interstrand cross-links in Fanconi's anemia cells of defined genetic complementation groups. Mutat. Res. 184:271280.

38. Fornace, A.J., Jr., J.B. Little, and R.R. Weichselbaum. 1979. DNA repair in a Fanconi's anemia fibroblast cell strain. Biochem. Biophys. Acta. 561: 99-109.

39. Kaye, J., C. Smith, and P.C. Hanawalt. 1980. DNA repair in human cells containing photoadducts of 8-methoxypsoralen or angelicin. Cancer Res. 40: 696-702.

40. Friedberg, E.C., G.C. Walker, and W. Siede. 1995. DNA Repair and Mutagenesis. ASM Press, Washington, DC. 698 pp.

41. Hang, B., A.T. Yeung, and M.W. Lambert. 1993. A damage-recognition protein which binds to DNA containing interstrand cross-links is absent or defective in Fanconi anemia, complementation group A, cells. Nucleic Acids Res. 21:4187-4192.

42. Joenje, H. H. Youssoufian, F. A.E. Kruyt, C.C. dos Santos, R. Wevrick, and M. Buchwald. 1995. Expression of the Fanconi anemia gene FAC in human cell lines: lack of effect of oxygen tension. Blood Cells, Mol. \& Dis. 21:182-191.

43. Miyamoto, I., N. Miura, H. Niwa, J. Miyazaki, and K. Tanaka. 1992. Mutational analysis of the structure and function of the xeroderma pigmentosum group A complementing protein: identification of essential domains for nuclear localization and DNA excision repair. J. Biol. Chem. 267:12182-12187.

44. Zhao, L.-J., and R. Padmanabhan. 1988. Nuclear transport of adenovirus DNA polymerase is facilitated by interaction with preterminal protein. Cell. 55:1005-1015.

45. Sommer, L., O. Hagenbuchle, P.K. Wellauer, and M. Strubin. 1991. Nuclear targeting of the transcription factor PTF1 is mediated by a protein subunit that does not bind to the PTF1 cognate sequence. Cell. 67:987-994.

46. Siomi, H., and G. Dreyfuss. 1995. A nuclear localization domain in the hnRNP A1 protein. J. Cell Biol. 129:551-560.

47. Wen, W., J.L. Meinkoth, R.Y. Tsien, and S.S. Taylor. 1995. Identification of a signal for rapid export of proteins from the nucleus. Cell. 82:463-473.

48. Fischer, U., J. Huber, W.C. Boelens, I.W. Mattaj, and R. Luhrmann. 1995. The HIV-1 Rev activation domain is a nuclear export signal that accesses an export pathway used by specific cellular RNAs. Cell. 82:475-483.

49. Savitsky, K., A. Bar-Shira, S. Gilad, G. Rotman, Y. Ziv, L. Vanagaite, D.A. Tagle, S. Smith, T. Uziel, S. Sfez, et al. 1995. A single ataxia telangiectasia gene with a product similar to PI-3 kinase. Science (Wash. DC). 268:1749-1753. 